\title{
The Impact of Changes in Chinese Government Policy on Rural-Urban Migrant Children's Schooling
}

\author{
Nan $\mathrm{Li}^{1}$ \& Peggy L. Placier ${ }^{2}$ \\ ${ }^{1}$ Gustavus Adolphus College, St. Peter, Minnesota, USA \\ ${ }^{2}$ University of Missouri, Columbia, Missouri, USA \\ Correspondence: Nan Li, Gustavus Adolphus College, St. Peter, Minnesota, USA. E-mail: nli@gustavus.edu
}

Received: October 26, 2014 Accepted: April 9, 2015 Online Published: June 5, 2015

doi:10.5539/ass.v11n18p31 URL: http://dx.doi.org/10.5539/ass.v11n18p31

\begin{abstract}
In this policy analysis we will explicate changes in policies affecting the ability of Chinese rural-urban migrant families to gain access to public school education for their children. We argue that these changes are traceable to a contradiction between the transformation of government economic policies in the period since 1978, which encouraged rural surplus labor force to move to urban areas seeking job opportunities; and the Hukou policy, which continued to label migrants as "urban outsiders" (Cheng shi wai lai ren kou translated into Chinese) and therefore limited migrant families' access to resources and services intended for urban residents. Recent changes in policy have attempted to resolve this problem, but our case study findings show that the cultural and social divide between rural and urban residents remains a salient factor in urban education.
\end{abstract}

Keywords: Hukou policy, migrant workers, migrant children, rural-urban migration

\section{Background of China's Internal Migration and Accompanying Problems}

\subsection{Causes and Consequences of Urban Migration}

China began experiencing a large wave of internal migration after free market economic reform beginning in the late 1970s. Between 1980 and 2000, 268 million Chinese migrated from their rural hometowns to urban areas (Yusuf \& Nabeshima, 2008). According to statistics released by the Ministry of Agriculture in 2004, 114 million rural surplus laborers moved from their rural hometowns to urban areas seeking employment opportunities. Accompanying this rural labor migration, China is experiencing a rapid rate of urbanization. Before the 1970s, the rural population comprised $80 \%$ of the total population; today, of 1.26 billion people in China, $36.02 \%$ live in urban areas (National Bureau of Statistics of China, 2001). In 2007, about 10\% of the population in China was rural-urban migrant workers (Kwong, 2011).

With this large-scale internal migration and urbanization, laws and regulations established before China's economic reform did not match the needs of the free market economic reform and the fast pace of the urbanization process. Therefore, institutional barriers in urban areas put Chinese migrant workers in a disadvantaged position in the urban society, making their adaptation to urban life full of challenges and hardships. This study focused on the difficulties and inequities faced by migrant children in one urban public school system. Lu \& Zhang (2004) outlined two related elements that contribute to migrant children's difficulties in getting access to public education resources: Hukou policy and urban-rural divide.

\subsection{Impact of the Hukou Policy}

Under the Hukou system, Chinese citizens are divided artificially into two groups: urban residents (those born in urban areas) and peasants (those born in the countryside). In 1958, the central government established the Hukou policy with the original purpose of restricting rural-to-urban migration. Basically, Hukou registered each individual's birth place and birth date. If an individual needs to leave his/her birth place (e.g. a rural village) to go to college or take a job in a metropolitan area, he/she has to obtain relocation permission from the local urban police station. Thus, the Hukou policy draws a clear line between rural or urban identities.

Before the 1970s, it was extremely difficult for farmers to move to cities to seek job opportunities due to the government's tight control of social mobility and rigid centralized market economic system. Cheng and Selden (1994) described the Hukou policy as a system that was "integral to the collective transformation of the countryside, to a demographic strategy that restricted urbanization, and to the redefinition of city-countryside 
and state-society relations" (p. 644). The key to understanding the Hukou policy was state control of its residents' mobility and freedom. This household registration system tremendously restricted individuals' freedom of residential and work choice. Meanwhile, the Chinese government traditionally allocated more public-service funding to urban residents than that to rural residents. As Cheng and Selden (1994) observed,

urban areas are essentially owned and administered by the state, and their residents are the state's direct responsibility. The state budget must supply urban areas with employment, housing, food, water, sewage disposal, transportation, medical facilities, police protection, schools, and other essentials and amenities of life (p. 644).

For example, urban residents were entitled to a comprehensive social welfare system---including subsidized housing, affordable medical care, unemployment insurance, and subsidized public education system (Leung \& Nann, 1995). In contrast, rural residents did not receive much support from the state's funding to finance a comprehensive welfare system. In fact, the funding channel for rural social welfare is locally-based, and programs receive limited funding from less affluent rural communities (Leung \& Nann, 1995). Disparity of public resource utilization between urban residents and migrant workers is a hotly-debated issue in current China.

Public resource utilization includes access to education. According to Wang (2010), about $27.5 \%$ of school-age children living in Beijing were migrant children who followed their parents from their rural hometowns. One of the most salient problems that migrant families experience is that they undergo obstacles in sending their children to public schools in the host cities. According to the Hukou policy, the local district's sole responsibility is to educate children who are born in their judicial administration zones; it does not extend its responsibility to those people not registered in their district. Local governments in the host cities have no obligation to provide educational resources to migrant children who have a rural Hukou. The Hukou policy is the root of migrant children's difficulty in obtaining full access to public educational resources in the host cities (Xia, 2006). However, some public schools in urban areas want to raise their revenue, so they set aside a certain quota to enroll a small number of migrant children by charging them additional tuition fees.

\subsection{The Urban-Rural Divide}

Although migrant workers provide cheap labor to fuel China's urbanization process, they were excluded from many benefits and public services that urban governments provide to their urban residents. Lu (2005) stated that migrant workers lacked access to subsidized housing, health and unemployment insurance, and the urban public education system which prioritized urban residents. Migrant workers or Nongmin gong (in Chinese literal translation) carries a derogatory meaning indicating their peripheral position as farmers and sojourners in urban society. Migrant workers in urban areas belong to neither their rural hometowns nor the host cities where they work as transient workers. Their marginalized position in urban stratification is reflected in the multiple ways:

- Economically, migrant workers' income is low compared to that of their urban peers. Furthermore, their employment is focused on manual jobs or in low-paying service industry sector (Luan, 2003).

- Politically, migrant workers do not have power to form unions or mobilize organizations although they are the outcast class in urban society (Cheng, 1994).

- Socially, they are excluded from micro-level community participation activities such as getting full access to local public education systems in host cities for their children, and on the macro-level being turned down by the urban public service system due to their rural Hukou (rural identity) (Wang, 2007).

Furthermore, the Hukou policy has a strong stigmatizing effect on migrant families' daily lives in urban areas. Migrant workers are constantly criticized for burdening urban resources and infrastructure and engaging in crimes (Cai, 1995; Solinger, 1999). Since migrant families do not hold a local urban Hukou, they are excluded from the desirable and highly-paid jobs available to urban residents (Fan, 1999). Instead, migrant workers often take low-paying, labor-intensive, and long-hour manual jobs which urban residents are not willing to take. This creates the lowest social stratum within the host cities. The artificial divide created by the Hukou policy makes migrant workers and their children constantly feel marginalized in the host cities (Han, 2004; Kwong, 2004; Lu \& Zhang, 2004; Ngok, 2007).

Several studies conducted by Chinese scholars reported that migrant families had encountered discrimination at work as well as in public. Lu and Zhang (2004) found that migrant families perceived themselves as placed in a peripheral social stratum between rural and urban residents. They conducted a survey study of one hundred and fourteen schools in Beijing in 1999. The authors interviewed individual migrant children to learn about their schooling experiences in Beijing. According to their study, a main theme found in the study was the extreme 
poverty experienced by migrant children and its tremendous impact on their attitude towards schooling and life in general (Lu \& Zhang, 2004). A migrant child attending a local public school stated in his composition that : "I think when I grow up, I must make a lot of money to take care of father and mother... my family sells vegetables, and although we are poor, I must study hard, excel" (p. 60). The low income of the migrant workers in some cases motivates their children to study hard to get out of poverty, but they may not have access to the opportunities that would allow such upward mobility. According to Kwong (2004), a migrant family has to pay an additional 3480 Yuan (\$535) in addition to the 300 to 400 Yuan (\$60) tuition fee which is charged to every local student if a migrant child is to attend public schools in the host cities. It is safe to say that high cost of attending urban public school prevents migrant children from gaining full access to educational resources intended for urban residents.

\subsection{Role of Education in Chinese Culture: A Shared Value}

According to traditional Chinese culture, education is the only way for a person to achieve social mobility. In other words, being able to receive good education is an important predictor of one's future social status. Migrant workers and their children are constantly ridiculed by their urban peers because they are poorly-educated. In her study of migrant children's schools in Beijing, Kwong (2004) found that local governments viewed the migrant community as "a source of trouble and believe that because the parents brought the children to the urban areas, the children are the parents' responsibility and not the urban government" (p.1082). Migrant workers have lived a harsh life, and they want their children to be successful. Huang and Xu's survey study (2006) of more than two hundred migrant families in Hangzhou (a big city in the east coastal area of China) indicated that $72.3 \%$ of the surveyed migrant workers wish their children to receive college or above education.

China has a long history of valuing education, and this value is shared by migrant workers. When they encounter difficulties in accessing public education resources in the host cities, many migrant parents have to look for alternative ways to educate their children. In general, migrant workers have two choices. One choice is to pay an additional "education rental fee" (Jiedu fee in Chinese) to the public schools and the second choice is to send their children to poorer quality private schools established primarily for migrant children. The first choice is often out of reach for migrant families because public schools charge high fees to students who are born outside the geographical area of the school district. Due to the expensive tuition fee charged to non-local residents, a large number of private "migrant children's schools" have been established and developed in the host cities. However, studies and news stories have documented a plethora of problems in such schools. In addition, local governments' unsupportive attitude towards migrant children's schools also complicates migrant students' schooling experience in the host cities (Ding, 2004; Han, 2004).

\section{Studies of Rural-Urban Migrant Children's Schooling}

Chinese scholars and researchers approach the study of migrant children's schooling problems from various perspectives. From a cultural deficit perspective, Shen (2006) stated that there were major problems in migrant education and a lack of societal concern about migrants in urban areas. Shen pointed out that due to limited education of migrant parents, they did not possess cultural resources and thus failed to create a proactive learning environment for their children at home because of their out-of-date family education philosophy. The author further stated that migrant parents ignored the role of family education and did not have a harmonious communication style with schools.

In contrast, Li and Huo (2007) and Zhang and Wang (2008) looked at migrant children's schooling experiences through sociological conflict theory. $\mathrm{Li}$ and Huo found that migrant children were discriminated against in urban schools. This discrimination was reflected in the following aspects: they did not enjoy equal educational opportunity from the very beginning; when they started school, their educational experience was full of unfairness; and there were unfair regulations and rules regarding migrant children's education. Furthermore, this unfairness created a marginalized group in urban society, because their marginalized status in host cities would pass down from generation to generation. Similarly, Zhang and Wang (2008) held that many societal practices discriminated against migrant children when they went to school in urban areas. For example, migrant children did not receive adequate educational facilities and resources. Migrant families' values and ideology were not recognized by their urban counterparts, which led to an ultimate result of their not being able to obtain an equal educational opportunity in host cities.

Liu (2004) pointed out that the most direct barrier to migrant children's schooling experience in urban areas was institutional. This institutional barrier required migrant children to go to public school within their permanent residential place stipulated by the Hukou policy. Meanwhile, the decentralized funding channel of compulsory education's financing system also contributes to migrant children's difficult schooling experiences in the host 
cities. The traditional educational resource distribution policy, distributing less funding to rural schools, has influenced migrant children's entitlement to receive public education.

In summary, Chinese scholars have identified major reasons for migrant children's schooling problems as the Hukou policy, the inequitable financing system, and societal discrimination (Li \& Wang, 2009). Findings of Chinese scholars' studies of migrant families caught the Chinese governments' attention, leading to policy changes in recent years.

\section{Policy Responses to Migrant Children's Schooling Problems}

Prior to the mid-1990s, migrant children were discouraged from attending public schools due to the rigid Hukou policy. However, as China rapidly urbanized, the Chinese government realized the importance of maintaining a rural-urban labor pool. A series of regulations aimed at solving migrant children's schooling problems were issued in 1996, 1998, 2001, and 2003 respectively.

\subsection{6 - Temporary Regulations on Schooling of Migrant Children (Trial Measures)}

These regulations were issued on April $2^{\text {nd }}, 1996$ by the State Education Bureau and the Ministry of Public Security. These regulations showed the Chinese central government's initial awareness of migrant children's schooling problems. In these regulations, the government held that only those migrant children who had the capability to learn could attend urban public school. Unfortunately, the 1996 regulation promoted a discriminatory image of migrant children, by questioning their learning capability.

Two articles in this ordinance are worthy of mention. Article 3 gave the definition of "migrant children" referred to children aging from 6 to 14 years old (or from 7 to 15 years old) and who had the capability to study. One interesting point of this definition lies in the language of "have the capability to study." We view this language as carrying derogatory meaning inferring that some migrant children are not smart enough to attend public school in urban areas. Article 6 pointed out the role of the Hukou policy which played out in migrant children's educational placement. Article 6 stated that:

For migrant children who have guardians in their place of origin where their Hukou (birth place record and its corresponding house hold registration record) is issued, they must go back to their original birth places to receive compulsory education, if there is no guardian in their original residential places, they shall receive compulsory education in the host city.

From the language of Article 6, one can see clearly that migrant families do not have freedom in choosing their children's educational placement in urban areas due to their rural Hukou (rural identity).

\subsection{8 - Provisional Regulations for Schooling of Migrant Children}

On March 2, 1998, State Education Bureau and Ministry of Public Security issued another set of regulations defining migrant children and revealing a power relation between migrant families and local urban governments. Article 2 defined "migrant children and juveniles" as those children aging from 6 to 14 or 7 to 15 years old, who had lived with their parents or guardians in the host city for 6 months or more, and who had the capability to study. One can see that this 6 month residential period brought migrant children's education to a sudden stop once they moved from their rural hometowns to the host cities. One cannot help wondering who was going to take care of those migrant children if they must stay at home for 6 months before applying for public school in the host cities. Another problem introduced by this regulation was that migrant children would experience a lag in their education during the six month period, causing them to fall even further behind their urban peers.

Article 8 of the 1998 regulation gave the detailed procedure on how a migrant family could approach the urban public education system if the family wished to send their child to a local public school. Article 8 stated that:

For those migrant children who wish to receive compulsory education in the host city, their parents/guardians should receive approval from the county/township-level government where their children's permanent residential permit registered in the Hukou record is issued. Then they can apply for admission to schools which are close to their temporary living quarters in the host city. After the school approves migrant children's application, then they can be allowed to audit the class.

Again, the Hukou policy played a vital role in migrant children's educational choices in urban public schools. The language of Article 8 also reveals a certain power relation between migrant families and local urban governments in a sense that migrant families have to receive approval from two governments -- their rural hometown governments and urban governments. This 1998 provisional regulation puts migrant families in a subordinate situation in that their children's fate of whether being able to attend public school in urban areas is held in the hands of the governments. 


\subsection{1 - National Development Program for Children's Wellbeing (2001 to 2010)}

Issued by the State Council, the major theme of this program was to promulgate nine years of compulsory education comprehensively, ensuring all children's entitlement to receive education, and to basically ensure access of the nine-year compulsory education to migrant children. This program further stated that the governments should take practical measures to guarantee a nine-year education to orphans, students with disability, and children of migrant workers. From the letter of this program announcement, we can see that the Chinese central government wanted to implement compulsory education among all children. However, children of migrant workers were placed in a same peripheral group as people with disabilities and orphans.

According to the Western tradition in legal studies, people with disabilities are historically discriminated against, and are considered to be "vulnerable populations." Thus there is a need for more scrutiny when their rights are violated. From this, we can make an inference that children of migrant workers were placed in the same classification. There is progress, but the inference is still a stigmatizing one. Nevertheless, the 2001 regulation expressed the Chinese central government's wish to implement compulsory education among all children regardless of their Hukou status. The Chinese central government did admit that it was the State's responsibility to ensure educational rights for all children.

\subsection{3 - Circular of the Opinion on Bettering Education of Migrant Children}

In September of 2003, the General Office of the State Council issued the most important and detailed government document on how to deal with migrant children's schooling problems. This circular spelled out specifically whose responsibility it was, among various government branches, to ensure educational rights of migrant children. For example, the circular stated that:

The host city should be responsible for educating migrant children. The local public schools and local education administration bureau need to establish a comprehensive system to ensure and improve migrant children's schooling experience in receiving compulsory education. Local public schools should try their best to enroll migrant children and integrate them into daily school activities, treating migrant children the same as local urban students. Schools should enhance communication with migrant children's families and learn about their family condition, help migrant children overcome psychological barriers and adjust themselves to the new learning environment.

The 2003 Circular is different from any other ordinance in that for the first time, the Chinese central government required local governments at various levels or different government branches in the same city to cooperate with each other and guarantee not only migrant children's right to receive education but also enhance the quality of their schooling experience in the host cites. The 2003 Circular is the most effective policy, because it stipulates concrete responsibilities assigned to various government branches. The 2003 regulation also points out that it requires team efforts among various government branches to ensure migrant children's smooth schooling experience in the host cities. It seemed that the 2003 Circular would meet migrant children's schooling needs in a satisfactory way. However, researchers found that problems still existed in migrant children's schooling experiences in urban areas.

The adoption of these four regulations moved the policy process from unfairness to near fairness, from using abstract and discriminatory language to sending positive messages of helping migrant children stay in public school in urban areas. In order to better understand the institutional discrimination (Xiong, 2010) and new problems that Chinese migrant families are facing under a social climate of more relaxed government enforcement of the Hukou policy, the first author of this article conducted a case study in Chengdu, China in spring of 2010.

\section{Research Design and Aims}

The findings for this article derived from a larger exploration of the experiences and lives of migrant and urban families in Chengdu. Based on the previous literature and policy developments, we wanted to know if the Hukou policy and urban-rural divide still influenced the education of migrant children.

\subsection{Research Questions}

In this study we address the following questions:

1. What factors influence migrant families' decisions on sending their children to receive compulsory education in the host city of Chengdu? In contrast, what factors do urban families take into consideration when they send their children to school? 
2. Is there continuing evidence that the Hukou status (rural-urban identities) and the urban-rural divide influence schooling in Chengdu?

\subsection{Setting}

Our research is situated in one major city, Chengdu, an important political, economic and cultural center in Southwest China. No previous studies had examined whether rural-urban migrant students' schooling experiences in Chengdu differ from those in China's major cities such as Shanghai and Beijing. Chengdu, the capital city of Sichuan province, issued a series of relevant policies regulating migrant children's enrolment procedure at public schools. For example, in March 2015, Chengdu Education Bureau publicized detailed procedures online for migrant families to enroll their children in public school within the migrant families' residential school district. According to the procedures, migrant families need to present the following documents to relevant school district offices and the school: the Hukou registration book of the family, applicant's identification card, a legal labor contract signed between the applicant (the parent of the school-age child) and the employer in Chengdu, and Chengdu residential permit. These procedures provide migrant families with written legal documents and to certain degree ensure their right to enroll their children in urban public school as they wish. However, this paperwork requirement poses an additional burden on migrant families.

\subsection{Research Design}

In the light of the research aims, a multiple comparison case study design was employed, with a sample of 5 local urban families and 5 rural-urban migrant families. Each family was composed of mother, father, and one child attending a local urban public school in Chengdu. The first author of this article gained access to participants through criterion sampling and theoretical sampling methods (Patton, 2001). In order to obtain access to the participants, the first author contacted a local construction company's manager in Chengdu by submitting a brief letter informing the manager of the research purpose and the sample-selection criteria. The manager recommended five qualifying participating families. The participating families were chosen through the following criteria: each migrant family's monthly income is below RMB2500 Yuan (about \$356), both husband and wife are migrant workers working in Chengdu, and at least one child in the family attends a local public school. The migrant families have lived in Chengdu for many years; they are not newcomers to the city, but are still identified by their Hukou as "rural." Five urban families via a convenience sampling procedure are identified by the first author. The monthly income range of these five participating urban families varies between 8000 Yuan (\$1143) to 12000 Yuan (\$1713).

The research approach was qualitative, and the data reported in this article were generated through individual family interviews with 10 urban parents, 10 migrant worker parents, 5 urban children, and 5 migrant children. A semi-structured interview was conducted with each individual family composed of mother, father, and a child. The interviews were conducted in the participants' home language, the Sichuan dialect of Chinese language, and were audio-recorded. The first author translated and transcribed all the interview conversations immediately following each interview. All names for individuals and schools were replaced by pseudonyms. A grounded theory approach (Charmaz, 2006) was employed to sort, code, and analyze the rich data.

\section{Major Findings}

\subsection{School Choices}

With regard to the two groups' decisions on their child's educational placement, it was a general trend that the urban families used quality of a school's education as their most important indicator in choosing the school for their child. In fact, four out of five participating local urban families in our study sent their child to either an expensive private school or a quality public school outside of their district by paying costly extra school selection fees. One dentist mother paid about RMB20, 000 Yuan (\$2857) to a quality public elementary school as a one-time non-refundable deposit fee for her 7 year old daughter whose residential location is outside that school district. In contrast, almost all migrant families took the cost of tuition fees as the most important factor into consideration when they sent their child to a local urban public school. In fact, only one migrant worker mother in this study sent her 9 year old son to a better quality public elementary school by paying one -time out-of-school-district fees of RMB 5000 Yuan (\$714) plus regular semester tuition fees charged to local urban children.

\subsection{Continuing Relevance of the Hukou}

Previous literature found that the Hukou policy, Jiedu fees (educational rental fees), and urban-rural divide were three salient elements contributing to migrant children's difficulties in getting access to public education resources in host cities (Lu \& Zhang, 2004). According to the participants interviewed in our study, since 2007 
the Jiedu fees (educational rental fees) are no longer the obstacle to migrant children living in Chengdu who wish to attend urban public schools. According to one migrant worker father, today all public elementary schools and junior middle schools in Chengdu have abolished charging migrant families educational rental fees as long as the family lives in a residential area within their neighborhood school district. However, in our study, the negative effect of the Hukou policy is evident in the complex registration process for migrant children who attend urban public schools.

\subsection{Rural-Urban Divide}

We found an obvious "insiders/us" vs. "outsiders/them" divide between local urban residents and rural-urban migrant workers. The participating urban residents and migrant workers use "us" and "them" in their conversations indicating that they neither belong to each other's social circle nor see themselves as part of the same community. It is true that migrant workers are allowed to live in the host cities temporarily for their work, but when we look at their living and work environment, we can see that they live in a completely different social space (habitus) from that of their urban counterparts no matter how long they have lived in Chengdu. All five participating migrant workers' jobs were similar in nature in a sense that almost all those jobs were labor-intensive, low-skilled, poorly-paid, and a few of them even potentially hazardous jobs which urban residents are not willing to take. In comparison, local urban residents have more choices by having enough financial support as well as families and friends nearby for support. As Solinger (1999) pointed out, the undesirable jobs that migrant workers held in the labor market put them in an inferior position in urban society. Furthermore, migrant workers are constantly viewed as a source of "urban crowdedness" and "intensive job competition" as expressed by the participating urban families in the interviews.

The rural-urban divide in migrant children's lives is shown through their attending segregated schools in Chengdu. Three out of five migrant families in this study sent their children to Sunflower School where $90 \%$ of the students were migrant children. The Sunflower School was located near a vegetable and meat market. Before the market was established, a majority of its students were local urban children. However, after the market was established in the middle 1990s, a large number of rural-urban migrant workers sought job opportunities in this market and they brought their children along. Now Sunflower School has earned a reputation as "a school for migrant children."(Nongmin gong zidi xiao translated into Chinese language). The other two migrant children went to an urban public school near their living quarters. However, four out of five local urban children attended expensive private schools. One urban child went to a quality public school outside her residential school district after her parents paid an excessive "school selection fee" of RMB 20,000 Yuan (\$2857).

\section{Evidence from Case Studies}

\subsection{Mei and Zhang}

Mei, a 41-year-old female personal banker attributed Chengdu's "crowdedness" to migrant workers' large influx of migration to Chengdu. Mei and her husband Zhang were born in Chengdu. They both worked for a major state bank and lived an upper-middle class life. Their daughter Niu attended a private boarding elementary school in Chengdu. The couple seldom cooked at home. They received free breakfast and lunch at their work place's dining hall, and they dined out every day at dinner time. They picked up their daughter Niu on Friday afternoons and then the entire family would drive to Zhang's mother's house to have a family meal. On Saturdays and Sundays, they either drove to Chengdu's outskirts for a one- day trip or Mei took Niu to museums, movies, shopping malls, etc. Mei and Zhang owned two housing properties in Chengdu and one sedan. Their daughter Niu traveled every summer; for example, Niu and her classmates went to Singapore for seven days and she was planning to visit $\mathrm{Xi}$-an, a well-known ancient city where terracotta army men were unearthed.

This sounded like a happy and affluent urban family. However, the first author was much surprised when Mei indicated how much pressure she felt when finding herself surrounded by so many people. According to Mei, migrant workers are the "so many people" who have directly caused Chengdu's "over-crowdedness." When the first author asked Mei what she thought of migrant workers' move to Chengdu in recent years, she responded:

I think the development of Chengdu needs those migrant workers but I also feel that a large number of migrant workers' coming to the city brings inconvenience to our life. For example, I had a hard time to get on the bus after I am off work around 5:30 p.m. every day. The problem now is not about traffic jam any more but about the fact that there is no way I can get on the bus because there are often at least 5 or 6 layers of people waiting for the bus in the downtown area between 5:30 p.m. and 6:30 p.m. I feel surrounded by people everywhere when I go shopping or dine out. Before, I felt Chengdu was a relaxing leisure city, but now I feel it is too crowded and Chengdu becomes a city without convenience. I also feel depressed when seeing so many people around me. 
Mei seemed to be very concerned about Chengdu's "crowdedness." Furthermore, she believes this "crowdedness" is brought by the migrant workers who flock to Chengdu city to seek job opportunities.

\subsection{Hong and Gang}

Another young urban resident called Hong working for Chengdu Grid (a government-run utility company in Chengdu). She viewed migrant workers as adding competitiveness to the already tight job market in Chengdu. Hong was a 36 year old government staff. Her husband Gang was an airport shuttle driver. Hong and Gang had a 7-year-old daughter called Lan. The family owned a sedan and a 3-bedroom apartment unit in the northern part of Chengdu city. Like the typical work schedule of government officials, Hong worked from 9:00 a.m. to 5:00 p.m. Monday to Friday. Gang worked for 24 hours per shift. After one shift, he took two days off. Therefore, he worked only ten days each month. The young couple, together with their daughter Lan, lived with Hong's parents. Hong's parents cooked and did other house chores for the young couple while they were at work. In China, it is common to see a young married couple live with their aging parents due to expensive urban housing and the couple's busy work schedule. In addition, most Chinese grandparents are happy to live with their married children and enjoy taking care of their grandchild.

At the interview, Hong and Gang told the first author that at their work place, there were many migrant workers, but they never developed friendships with each other beyond their working relationship. When the first author asked the couple what they thought of migrant workers' migration to Chengdu, Hong responded:

At work, we have co-workers who are from the nearby countryside areas of Chengdu. Their salary is quite low and just enough for making ends meet, but we purchase health insurance for them. They do not have housing property as we do. I also feel that once migrant workers come to Chengdu, the competition of seeking a job becomes fierce. However, since I already got a job, I really do not care about that much.

Hong's husband Gang added:

Over 60 to 70 percent of the employees in my work place are from outside Chengdu. I get along with them. People in Chengdu are very tolerant of outsiders and we do not discriminate against them. As you know, in Shanghai, people in Shanghai discriminate against migrant workers. We are not like those Shanghainese. Chengdu people are very tolerant...

Gang's comments on typical Shanghai residents' discriminating attitude towards migrant workers are consistent with Feng, et al.'s survey (2002) findings that rural-urban migrant workers are segregated from local urban residents. Feng, et al. further argued that the social divide between urban and rural areas in Shanghai may contribute to "the formation of a dual society in urban China" (p. 520). It was interesting to see Hong and Gang deliberately emphasized Chengdu people's "tolerance" of migrant workers, but meanwhile Hong thought migrant workers came to the city to grab "their" ("local urban residents") rice bowls. It is obvious to us that there is a certain boundary between urban residents and migrant workers in the host city of Chengdu.

\subsection{Luo and Ren}

Among the five migrant families whom the first author interviewed, none of them claimed that they had made friends with local Chengdu residents either. Luo and Ren's daughter Hua was a $5^{\text {th }}$ grader at Sunflower School. She was soon going to graduate from elementary school. Hua's parents moved to Chengdu in 1993. They ran a clock/watch-fixing store in the downtown area of Chengdu. Hua had a younger brother called Jun who was eight years old and attended the same school. Hua, Jun, and their parents lived in a rented two-bedroom apartment unit near a vegetable and meat market in the downtown area of Chengdu.

Hua's father Ren was thirty-four years old. He came to Chengdu when he was only seventeen. Ren learned how to fix watches and clocks from his brother-in-law who came to Chengdu in 1991. At the age of twenty-one, Ren opened his own clock/watch fixing store in Chengdu. The first author visited their store. It was tiny with an area of about 12 square meters. Ren told the first author that his store had never moved. He and his wife Luo had run this family store for almost thirteen years. The first author felt that Ren and Luo must have stable financial resources; otherwise, it would be very difficult for the couple to raise two children in an urban area such as Chengdu. Ren and Luo had a fixed work schedule from 9:00 a.m. to 6:00 p.m. every day.

Luo indicated that most of their customers were local urban residents. When the first author asked Luo whether she and her husband made friends with them, she said no. The first author further asked the couple's daughter Hua about how she felt about her urban neighbors, this 12-year-old girl responded wittily: "We do not know any urban neighbors here. After we get home, we all close our doors. We do not disturb each other." Her mother Luo added later: "Our personalities are easy-going. We do not fight with others for getting our own benefits so we get along with urban people." It was interesting to see that urban people use the word "tolerance" to describe how 
they feel generous about migrant workers' moving to Chengdu. Then this migrant family used the words "easygoing" and "do not disturb each other" to indicate they really "get along" with their urban peers. It is obvious that although migrant workers and urban residents live in the same city, Chengdu, they live separately in their own life circles.

6.4 Xue

Among those migrant children attending urban public schools, their parents indicated that they had undergone complex registration processes in order to send them to school in their temporary urban residential district. One migrant worker mother named Xue shared her "frustrating" experience in dealing with local urban school administrators when registering her son in a local public school. Xue indicated that she was asked by her son's school to show paper work at the beginning of every fall semester so her son could attend the school without paying extra fees. She viewed this redundant requirement of presenting the paper work to the school every single year as the school's deliberate intention of trying to get money from her. As she told it,

Dong, my son, went to school in the fall of 2008. Since we had purchased a housing unit here in Chengdu, we were granted a Chengdu Hukou, and we did not need to pay any extra fees. Otherwise, we would pay the so-called school sponsoring fee (jiaoyu zanzhu fee) to the school. To enroll Dong at Orange Garden School, I have to show three forms of paper work every year to his teacher: Dong's Hukou book, our housing property purchase proof, and the permanent residential permit issued by Chengdu Police Station. Dong's school asked us to show all the three paper work every year. Their intention is to set up obstacles so if we fail to show paper proof to them in a single year, they would get big money by charging us extra fees (jiaoyu zanzhu fee). For example, if your Hukou registration place is not within the school's administration zone and you are not able to show the permanent residential permit in Chengdu and other relevant paper proof to the school, when you enroll your child in that school, they would charge you extra fees of up to RMB 20,000Yuan (\$2857). Furthermore, the school would ask you to sign a form indicating that you are willing to pay an extra one-time nonrefundable fee to sponsor the development of the school. But you know actually you have no other choice except for paying the extra fees if you wish to send your child to that particular school.

Accordion to Xue, Orange Garden School was still trying to charge extra fees to migrant students and their families if they failed to provide the school with relevant paper proof. At the Orange Garden School, the Hukou seemed to stand out as a deciding factor of influencing enrollment of migrant children.

\section{Discussion and Conclusion}

While our analysis of policy changes showed a gradual loosening of Hukou restrictions and widening access to public schools for migrant families, including in Chengdu, the case study results showed the continuing influence of rural and urban identities in Chengdu. Rural-urban migrant workers were a peripheral group in the host city. Their marginalized status was reflected in their low-skill jobs, limited resources, and challenges in dealing with the urban public school system when they enrolled their children in public school in Chengdu. Although the Hukou policy has been relaxed to the point of allowing peasants to move from their rural hometowns to urban areas to find work, the social divide created by the Hukou policy and the stigmatizing label it entails put migrant families in a disadvantaged position in the host city -- they lacked social networks and support in the urban community and their children were not fully integrated to urban environment. They could not afford to take advantage of opportunities to build cultural capital outside of schools or to choose better quality public or private schools. Thus, the stratification between local urban residents and rural-urban migrant workers in the host cities has become a long standing phenomenon.

In a highly stratified environment in the current Chinese urban society, educational problems that migrant children encounter cannot be solved by a single agency or only by schools. The state needs to establish sound and effective regulations to protect migrant families' rights including their children's right to not only gain access to public education in urban areas but also integrate themselves with local urban children via actively participating in various extra-curricular programs that the host city has to offer. Urban public school teachers need to step outside their classrooms and visit migrant workers' homes so to better understand the migrant children's home and community environment. Schools with a large number of migrant children might benefit from exposure to the work on "funds of knowledge" conducted in low income neighborhoods in the United States (González, Moll, \& Amanti, 2005).

It occurs to us that, in order to ensure an equal educational opportunity to migrant children who reside in urban areas, the first and most important strategy is to improve quality of life of migrant families if society truly wants to provide migrant children with an equal opportunity of receiving quality public education in the host cities. For 
example, Xiong (2010)'s field study in Shanghai indicated that although migrant children can enter urban public school within their residential school district, they were not fully integrated into school life with their urban peers. Instead, the rural-urban divide was reinforced in the public education system in Shanghai since some urban public schools grouped all migrant students into a separate class and even placed them in a separate building, thus forming a clear divide between migrant students and their local Shanghai peers within the same school. This "separate placement" of rural-urban migrant students attending Shanghai's public school echoes marginalized treatment received by migrant students in Beijing. According to Kwong (2011), some local urban Beijing students viewed migrant students as inferior and refused to speak or even play with them although the two groups attended the same public school.

Although our research is limited to one city and to a selected sample, and we cannot speak to the sample's representativeness, we conjecture that there may be a general trend of rural-urban migrant students being discriminated against in urban public schools despite the governments' proactive policy of allowing migrant children to attend public schools in their respective host cities. We recommend a larger study to substantiate this conjecture.

Given China's large scale rural-urban migration, achieving educational equity among all migrant children is not an easy task. It calls for the entire society's awareness of this peripheral group of migrants living in the host cities, and it also requires collaboration between government branches such as public welfare office, urban school districts, local police station, etc. The bottom line is that only when migrant workers' quality of life is improved, for example, through living in an inclusive urban neighborhood, and when the divide between "rural-urban migrant workers" and "local permanent urban residents" disappears, can education equity for Chinese rural-urban migrant children be achieved in the host cities. Migrant families, consistent with Chinese traditions, believe that education is the route to upward mobility, but that route for now is still blocked.

\section{References}

Cai, X. (1995). Zhonggong ongcun laodongli liudong yu renkou qinyi yanjiu zongshu [Summary of research on rural labor flows and population migration in China]. Nongcun Jingji Yanjiu Cankao, 2, 23-33.

Charmaz, K. (2006). Constructing grounded theory: A practical guide through qualitative analysis. Thousand Oaks: Sage Publications.

Cheng, W. (1994). The marginalized group in social mobility. In Hong Kong Asia-Pacific Research Institute (Ed.), Development and Inequality: Social class and Mobility in China's Mainland and Taiwan (pp. 137-156). Hong Kong: The Chinese University of Hong Kong Press.

Cheng, T., \& Selden, M. (1994). The origins and social consequences of China's Hukou system. The China Quarterly, 139, 644-668. http://dx.doi.org/10.1017/S0305741000043083

China National Bureau of Statistics (CNBS). (2001). Characteristics of Chinese rural migrants: 2000 (News Release, September, 10, 2001). Beijing: CNBS.

Ding, J. Z. (2004). Overhauling and regulating schools set up by migrants. Chinese Education and Society, 37(5), $10-28$.

Fan, C. C. (1999). Migration in a socialist transitional economy: Heterogeneity, socioeconomic and spatial characteristics of migrants in China and Guangdong Province. International Migration Review, 33(4), 954-987.

Feng, W., Zuo, X. J., \& Ruan., D. C. (2002). Rural migrants in Shanghai: Living under the shadow of socialism. International Migration Review, 36(2), 520-545. http://dx.doi.org/10.1111/j.1747-7379.2002.tb00091.x

González, N., Moll, L., \& Amanti, C. (2005). Funds of Knowledge: Theorizing Practices in Households, Communities, and Classrooms. New Jersey: Lawrence Erlbaum.

Han, J. L. (2004). Survey report on the state of compulsory education among migrant children in Beijing. Chinese Education and Society, 37(5), 29-55.

Huang, Z., \& Xu, K. (2006). Education of migrant workers and their children and its solutions. Journal of Zhejiang University (humanities and social sciences), 36(4), 108-113.

Kwong, J. (2004). Educating migrant children: Negotiations between the state and civil society. The China Quarterly, 180(4), 1073-1088. http://dx.doi.org/10.1017/S030574100400075X

Kwong, J. (2011). Education and Identity: the marginalization of migrant youths in Beijing. Journal of Youth Studies, 14(8), 871-883. http://dx.doi.org/10.1080/13676261.2011.607435 
Leung, C., \& Nann, R. C. (1995). Authority and benevolence: Social welfare in China. Hong Kong: Chinese University of Hong Kong Press.

Li, Q., \& Huo, J. (2007). Jihui pingdeng yu daiji gongzheng-guan yu nongming gong zinu jiaoyu wenti de shehui fenxi [Equal opportunity and generational justice-sociological analysis about educational problems of migrant children]. Shengyang Daxue Xuebao, 4, 82-85.

Li, Y., \& W., S. (2009). Nongming gong zinu jiaoyu wenti yanjiu shuping [Research synthesis of migrant children's educational issues]. Jinji Yanjiu Daokan, 10, 1-4.

Liu, Y. (2004). Dui liudong nongminggong zinu shou yiwu jiaoyu de zhiduxing fenxi [Institutional analysis of problems that migrant children encounter in receiving compulsory education]. Guizhou Shehui Zhuyi Xueyuan Xuebao, 2, 54-55.

Lu, S. H., \& Zhang, S. L. (2004). Urban /rural disparity and migrant children's education: An investigation into schools for children of transient workers in Bejing. Chinese Education and Society, 37(5), 56-83.

Lu, X. (2005). Zhidu shi Ruhe Zu'ai Woguo Nongcun Renkou Xiang Chengshi Qianyi De? Lun Zhidu dui Chengxiang Renkou Qianyi de Zuoyong Jili [How does institution prevent rural population from migrating to cities? An analysis of the effects of institutions of rural-urban migration]. Diaoyan Shijie, 6, 30-32.

Luan, J. (2003). Liudong Renkou de Shehui Tezheng Jiqi Shouru Yingxiang Xinsu Fenxi [Migrants' social characteristic and its income influencing factorial analysis]. Zhongguo Renkou Kexue, 2, 66-71.

Ngok, K. (2007). Chinese education policy in the context of decentralization and mercerization: Evolution and implications. Asia Pacific Education Review, 8(1), 142-157. http://dx.doi.org/10.1007/BF03025840

Patton, M. Q. (2001). Qualitative research \& evaluation methods. Thousand Oaks: Sage Publications.

Robinson. V., \& Garnier, A. (1985). Class reproduction among men and women in France: Reproduction theory on its home ground. The American Journal of Sociology, 91(2), 250-280. http://dx.doi.org/10.1086/228277

Shen, R. (2006). Chengshi nongming gong zinu jiaoting jiaoyu wenti ji duice [Urban migrant children's family education issues and its strategies]. Zhongguo Nongye Daxиe Xиebao: shehui kexиe ban, 3, 96-100.

Sichuan Education Bureau. (2015). Chengdu migrant Workers' Children's Enrollment Procedure Chart for Receiving Compulsory Education. Retrieved April 12, 2015, from http://www.cdedu.gov.cn/Information Disclosure/Show.aspx?id=48056

Solinger, J. D. (1999). Contesting citizenship in urban China: Peasant migrants, the state, and the logic of the market. Los Angeles: University of California Press.

Wang, C. (2007, August). Thinking about study "cultural capital" in mainland China. Paper presented at the annual meeting of the American Sociological Association, New York City, NY.

Wang, D. (2010). An analysis of migrant parents' school choice under the dual government policy. Jiaoyu Fazhan Yanjiu (Study of Educational Development), 12, 82-85.

Xia, C. L. (2006). Migrant children and the right to compulsory education in China. Asia Pacific Journal on Human Rights and the Law, 7(2), 29-74.

Xiong, Y. H. (2010). Urbanization of Children: Migrant Workers' Children's Identity Production and Political Socialization. Shanghai: Century Press, China.

Yusuf, S., \& Nabeshima, K. (2008) Optimizing urban development. In S. Yusuf, \& T. Saich (Eds.), China Urbanizes: Consequences, strategies, and policies (pp. 1-40). Washington, D.C.: The World Bank.

Zhang, S., \& Wang, Y. (2008). "shehui" paichi shijiao xiao de nongming gong zinu jiaoyu wenti [ Migrant children's educational issues from the "social discrimination" angle]. Changchun Gongye Daxue Xuebao: shehui kexue ban, 1, 117-120.

\section{Copyrights}

Copyright for this article is retained by the author(s), with first publication rights granted to the journal.

This is an open-access article distributed under the terms and conditions of the Creative Commons Attribution license (http://creativecommons.org/licenses/by/3.0/). 